\title{
Design, Synthesis and Antimalarial Activity of Novel, Quinoline-Based, Zinc Metallo-Aminopeptidase Inhibitors
}

\author{
Marian Flipo, ${ }^{\mathrm{a}}$ Isabelle Florent, ${ }^{\mathrm{b}}$ Philippe Grellier, ${ }^{\mathrm{b}}$ Christian Sergheraert ${ }^{\mathrm{a}}$ \\ and Rebecca Deprez-Poulain ${ }^{\mathrm{a}, *}$ \\ ${ }^{\mathrm{a}}$ UMR CNRS 8525, Institut Pasteur et Institut de Biologie de Lille, Université de Lille 2, Lille, France \\ ${ }^{\mathrm{b}}$ USM 0504 'Biologie fonctionnelle des protozoaires', Département 'Régulations, Développement, \\ Diversité Moléculaire', Muséum National d'Histoire Naturelle, FR CNRS 63 Paris, France
}

Received 11 March 2003; revised 8 May 2003; accepted 30 May 2003

\begin{abstract}
PfA-M1, a neutral zinc aminopeptidase of Plasmodium falciparum, is a new potential target for the discovery of antimalarials. The design and synthesis of a library of 45 quinoline-based inhibitors of PfA-M1 is reported. The best inhibitor displays an $\mathrm{IC}_{50}$ of $854 \mathrm{nM}$. The antimalarial activity on a CQ-resistant strain and the specificity towards mammalian aminopeptidase $\mathrm{N}$ are also discussed.

(C) 2003 Elsevier Ltd. All rights reserved.
\end{abstract}

\section{Introduction}

Malaria, caused by the parasite Plasmodium falciparum, is still prevalent and lethal in many countries. ${ }^{1}$ Chloroquine (CQ), exerting its antimalarial activity by inhibiting haemozoin formation in the food vacuole of the parasite, has been the standard drug for many decades. Unfortunately, the spread of resistant $P$. falciparum to this molecule has created an urgent need to develop new antimalarial treatments. ${ }^{2}$ In a project to find new quinoline-based antimalarials that would not induce resistance, unlike CQ, we have designed several compounds displaying a piperazine linker. Several of these compounds were active on the CQ-resistant strain $\mathrm{FcB} 1 .^{3}$

The recent publication of the genome of the parasite opens the opportunities of a better understanding of the biology of the parasite. ${ }^{4}$ This will hopefully result in the discovery of new specific targets to tackle with drugs. Proteases expressed in the erythrocytic stage of $P$. falciparum, for example, can be considered as interesting targets for the design of antimalarials. ${ }^{5,6}$

In particular, PfA-M1, ${ }^{7}$ a neutral zinc-aminopeptidase (M1 family), inhibited by the classical aminopeptidase inhibitor bestatin, has been proposed:

*Corresponding author. Tel.: + 33-3-2087-1217; fax: + 33-3-2087-1233; e-mail: rebecca.poulain@ibl.fr.
(1) to hydrolyze the small peptides generated in the food vacuole, during hemoglobin digestion by acidic endopeptidases (aspartyl, cysteine and metallo-endopeptidases), into amino-acids at the level of the cytoplasm, and: (2) to play a role in the erythrocyte re-invasion by the parasite. ${ }^{8}$ PfA-M1 shares a maximal homology in the active site region $(44 \%)$ with two human proteases: the human aminopeptidase-N and leukotriene A4 hydrolase. ${ }^{9}$

It is the only aminopeptidase of $P$. falciparum that has been purified and biochemically characterized. This enables the design and testing of potential inhibitors. Such compounds would help understanding the role of this enzyme and validate it as a therapeutic target.

In a project aiming at decreasing the potential for resistance occurrence of our quinoline-based antimalarials, we have designed dual inhibitors that would inhibit both the haemozoin formation and one of the proteases potentially involved in globin digestion. Such a strategy has been developed by Avery for the design of malarial cysteine proteases inhibitors based on mefloquine and chloroquine. ${ }^{10}$ The screening of several of our in-house quinoline-based compounds allowed us to identify compound 1 as an interesting inhibitor of PfA-M1, that served as a starting point for analoguing (Fig. 1).

We report here the design and parallel synthesis of a library of 45 non-peptidic analogues of $\mathbf{1}$, and its biological 


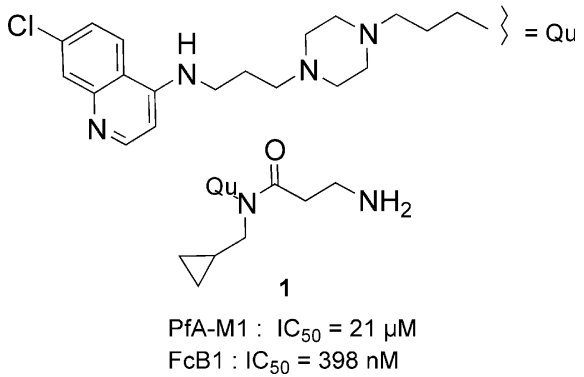

Figure 1.

evaluation on PfA-M1. Preliminary results on the antimalarial activity on $\mathrm{FcB} 1$ strain of the most active enzyme inhibitors, and preliminary specificity data on mammalian aminopeptidase $\mathrm{N}$, are presented and discussed.

\section{Chemistry}

PfA-M1 is a zinc-metalloprotease, of the M1 family, preferably cleaving basic, hydrophobic, as well as aromatic amino-acids. ${ }^{8} \mathrm{Zn}$-chelating groups are critical for the inhibition of such enzymes. ${ }^{11}$ To fulfill this function, we incorporated at least a carboxylic acid or an hydroxamate group in our molecules. In order to mimic the side chain of a Leucine residue, an isobutyl group (Ibu), analogue of the methyl-cyclopropyl moiety in $\mathbf{1}$, was also added in our potential inhibitors.

The 45 analogues ( 5 amines $\times 9$ carboxylic acids) have been synthesized at a 5 - $\mu$ mol scale, in parallel, according to the two-step procedure described in Scheme 1. The first step consists in the formation of the amide bond using PyBrop as the activator of the carboxylic acid followed by deprotection of the Boc and $\mathrm{tBu}$ groups of amines, hydroxamates and carboxylic acids.

The synthesis of this full combinatorial library required specific protected amines and carboxylic acids precursors to be synthesized prior to the coupling step.

Amines 3-6 (Fig. 2) all derived from compound 2 previously obtained from 4,7-dichloro-quinoline and 1,4bis-(3-aminopropyl)-piperazine by nucleophilic aromatic substitution. ${ }^{12}$ They were synthesized either by

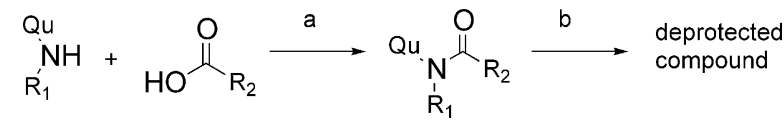

Scheme 1. (a) 1.1 equiv PyBrop, 2 equiv DIEA in DCM, overnight, rt; (b) TFA/DCM (20/80), $72 \mathrm{~h}, \mathrm{rt}$.

$\begin{array}{cl} & \text { R1: } \\ \text { Qu } & \text { 2: }-\mathrm{H} \\ \text { NH } & \mathbf{3}:-\left(\mathrm{CH}_{2}\right)_{2} \mathrm{COOtBu} \\ \mathrm{R}_{1} & \mathbf{4}:-\left(\mathrm{CH}_{2}\right)_{2} \mathrm{CONHOtBu} \\ & \mathbf{5}:-\mathrm{CH}_{2} \mathrm{COOtBu} \\ & \mathbf{6}:-\mathrm{iBu}\end{array}$

Figure 2. Amine precursors selected and synthesized for the library.

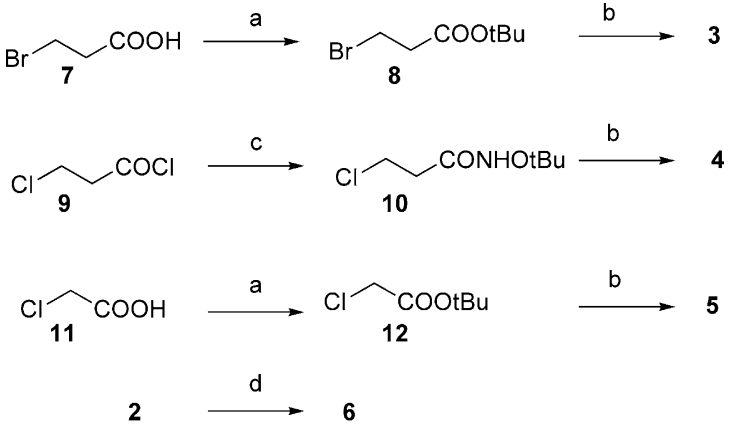

Scheme 2. (a) 1 equiv carboxylic acid, 0.7 equiv $\mathrm{BF}_{3}-\mathrm{Et}_{2} \mathrm{O}$ in $t$ - $\mathrm{Bu}-$ $\mathrm{COOCH}_{3}, 4 \mathrm{~h}$, rt; (b) 1.1 equiv amine 2, 1.1 equiv DIEA, EtOH, $15 \mathrm{~h}$, reflux; (c) 1.2 equiv $\mathrm{H}_{2} \mathrm{~N}-\mathrm{OtBu} \cdot \mathrm{HCl}, 2.4$ equiv pyridine, THF, $1 \mathrm{~h}, \mathrm{rt}$; (d) $1.1 \mathrm{HCOCH}\left(\mathrm{CH}_{3}\right)_{2}$, molecular sieves, 0.4 equiv DIEA, 6 equiv $\mathrm{NaBH}_{4}, \mathrm{MeOH}$, overnight, rt.

reductive amination of an aldehyde or $N$-alkylation with the appropriate halide (Scheme 2).

As for the carboxylic acid precursors, we synthesized malonic derivatives (24-28) according to the procedure described in Scheme 3. These moieties have been previously described in inhibitors of matrix-metalloproteases (MMPs). ${ }^{13}$ We also added to these in-house precursors, some commercially available $N$-protected amino-acids Lys, Leu, Phe, Asp (29-32, Fig. 3).

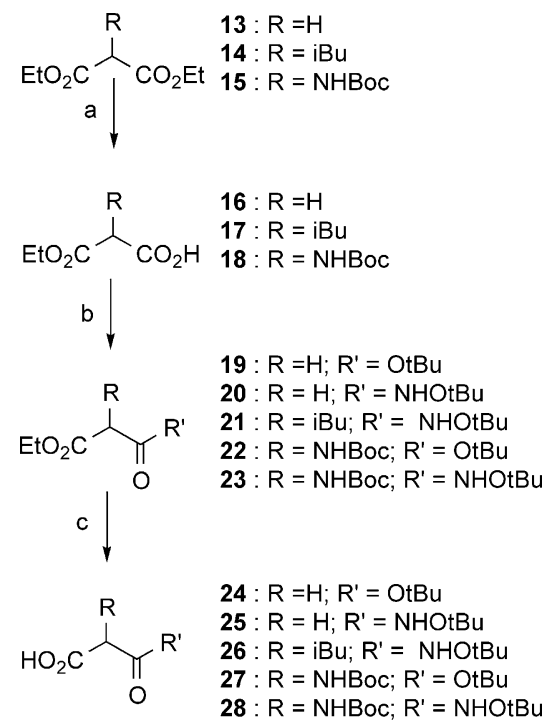

Scheme 3. (a) 1 equiv $\mathrm{KOH}, \mathrm{EtOH}, 2 \mathrm{~h}$, rt; (b) 1.2 equiv $t-\mathrm{Bu}-O$ $\mathrm{NH}_{2} \cdot \mathrm{HCl}, 1.2$ equiv DIEA, 1.1 equiv EDCI and 1.1 equiv $\mathrm{HOBt}$, THF, overnight, rt or 5 equiv $t$-Bu-OH, 4 equiv DIEA, 2 equiv 2chloro-1-methylpyridium iodide, acetonitrile, $2 \mathrm{~h}$, rt; (c) 3 equiv $\mathrm{KOH}$, EtOH, overnight, rt.

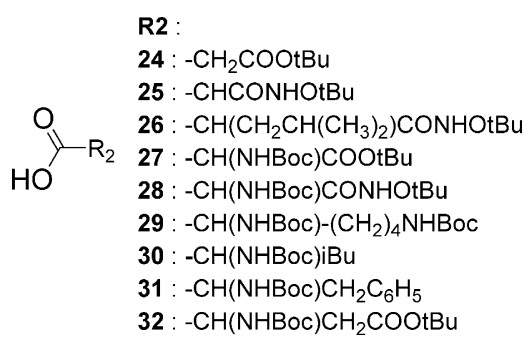

Figure 3. Carboxylic acids selected for the library. 


\section{Analytical control}

Each crude product was tested for purity using HPLC and identity using MALDI-TOF. In all cases, the purity exceeded $80 \%$ and the mass spectrum was consistent with the anticipated product structure.

\section{Biological Assays}

The analogues and the deprotected precursors were screened for their ability to inhibit PfA-M1 at $10 \mu \mathrm{M} .{ }^{14}$ Crude products displaying an inhibition percentage above $50 \%$ were selected for re-synthesis and $\mathrm{IC}_{50}$ determination on fully purified and controlled samples. The selected compounds were then tested for their ability to inhibit FcB1 parasite growth. ${ }^{15}$ The specificity against other aminopeptidases was evaluated in a model of mammalian aminopeptidase- $\mathrm{N}$ from porcine kidney. ${ }^{16}$

\section{Structure-activity relationships on PfA-M1}

Out of the 45 compounds tested at $10 \mu \mathrm{M}$, three compounds (33-35, Fig. 4), ${ }^{17}$ displayed a percentage of inhibition above threshold. Interestingly, they all derived from the same amine 6. After resynthesis and testing, they displayed $\mathrm{IC}_{50} \mathrm{~s}$ from 0.85 to $1.54 \mu \mathrm{M}$ on PfA-M1, that is, a $10-25$ times increase in potency comparing to compound $\mathbf{1}$ (Table 1).

The presence of a $\mathrm{Zn}$-chelating group is essential for the activity. Compound 33, the closest analogue of $\mathbf{1}$, bearing an hydroxamate is 10 times more active on the enzyme. In contrast, amine $\mathbf{6}$ is inactive. The hydroxamate group is more efficient than the carboxylic acid group. Carboxylic acids analogues of $\mathbf{3 3}$ and $\mathbf{3 4}$ were inactive. The isobutyl group is essential for activity, since
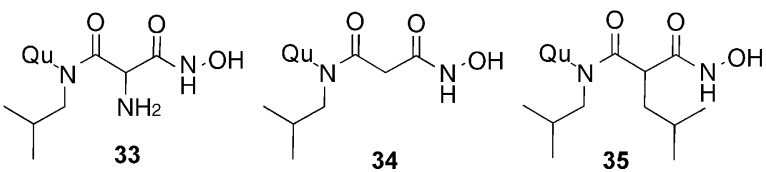

Figure 4. Best hits from the library on PfA-M1.

Table 1. Inhibition of PfA-M1 and of parasite growth, and specificity towards mammalian aminopeptidase- $\mathrm{N}$ of compounds 33-35

\begin{tabular}{lcccc}
\hline Compd & $\begin{array}{c}\text { PfA-M1 } \\
\text { inhibition } \\
\mathrm{IC}_{50}, \mu \mathrm{M}\end{array}$ & $\begin{array}{c}\text { Parasite growth } \\
\text { inhibition } \\
\mathrm{IC}_{50}, \mu \mathrm{M}^{\mathrm{a}}\end{array}$ & $\begin{array}{c}\text { Aminopeptidase } \\
\mathrm{N}(\mathrm{APN}) \\
\text { inhibition } \\
\mathrm{IC}_{50}, \mu \mathrm{M}\end{array}$ & $\begin{array}{c}\text { Ratio } \mathrm{IC}_{50} \\
\text { PfA-M1/IC }\end{array}$ \\
\hline CQ & $\mathrm{ND}_{50}^{\mathrm{b}}$ & $0.126(0.026)$ & $\mathrm{ND}^{\mathrm{b}}$ & - \\
Bestatin & 0.284 & 29 & 2.700 & 0.1 \\
$\mathbf{1}$ & 21 & $0.398(0.056)$ & 28 & 0.7 \\
$\mathbf{3 3}$ & 2.503 & $0.178(0.037)$ & 1.345 & 1.9 \\
$\mathbf{3 4}$ & 0.854 & $0.317(0.063)$ & 0.028 & 30.5 \\
$\mathbf{3 5}$ & 1.540 & $0.151(0.013)$ & 1.628 & 0.9 \\
$\mathbf{3 8}$ & $>10^{\mathrm{c}}$ & $1.380(0.050)$ & $\mathrm{ND}^{\mathrm{b}}$ & - \\
\hline
\end{tabular}

${ }^{a}$ Values are means of three experiments, standard deviation is given in parentheses. Strain is FcB1.

bND, not determined.

c $22 \%$ inhib $(10 \mu \mathrm{M})$.
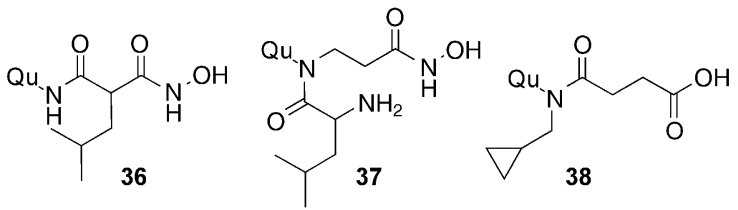

Figure 5. Inactive analogues 36, 37 from the screening and reference compound $\mathbf{3 8}$

the analogues of 33-35 without this moiety (derivatives of 2) were inactive.

The relative positions of the $\mathrm{Zn}$-chelating group and the isobutyl group are critical for the activity. For example, compounds 36-37 (Fig. 5) are inactive while displaying the same groups in a different 3D arrangement as respectively in $\mathbf{3 4}$ and $\mathbf{3 3}$. None of the analogues derived from the amino-acids (37 for instance) supposed to be recognized by the enzyme, was active, suggesting that the $\mathrm{Zn}$-chelating group should be supported by the carboxylic acid precursor.

The central position in malonic derivatives seems tolerant since it can accommodate with basic $\left(\mathrm{NH}_{2}\right)$ or hydrophobic (isobutyl) groups. Nevertheless, the best analogue, compound $\mathbf{3 4}$, is not substituted in that position. In particular, this suggests that an amino-group is not essential for the recognition by the enzyme although it is an aminopeptidase.

\section{Antimalarial activity and specificity}

The three PfA-M1 inhibitors are sub-micromolar inhibitors of the parasite growth. Their antimalarial activity is due to the inhibition of both PfA-M1 and haem detoxification. ${ }^{18}$ Interestingly, reference compound $\mathbf{3 8}$, displaying a $\mathrm{COOH}$ moiety at the same position as the hydroxamate $\mathrm{OH}$ in compound $\mathbf{3 4}$ (and a cyclopropylmethyl group instead of an isobutyl group), is weakly active on PfA-M1, and less active than $\mathbf{3 4}$ on parasite growth inhibition. Specificity for compounds $\mathbf{3 3 - 3 5}$, as expressed with the ratio of the $\mathrm{IC}_{50} \mathrm{~s}$ on the two targets, varies from 0.9 to 30.5 . The size of the substituant on the malonic methylene appears to be critical.

\section{Conclusion}

We have successfully designed non-peptidic inhibitors of PfA-M1, an aminopeptidase of $P$. falciparum. The quinoline moiety allows these compounds also to be inhibitors of haem detoxification, making these compounds potentially dual inhibitors of hemoglobin digestion. Yet the relative part of each mode of action needs to be determined. The three selected inhibitors 33-35 are active against CQ-resistant strain, thus validating their ability to cross membranes. The activity on PfAM1, and the specificity against other aminopeptidases such as mammalian aminopeptidase- $\mathrm{N}$ need to be improved. Such issues are under investigation and results will be reported in due course. Antimalarial activities and rough SARs emerging from this study, 
have encouraged us to pursue the optimization of PfAM1 inhibitors. Especially, we are now focusing on inhibitors devoided of the quinoline moiety.

\section{References and Notes}

1. WHO. World Health Report; WHO: Geneva, 2002.

2. Wellems, T. E. Science 2002, 298, 124.

3. Ryckebusch, A.; Deprez-Poulain, R.; Maes, L.; DebreuFontaine, M.-A.; Mouray, E.; Grellier, P.; Sergheraert, C. J. Med. Chem. 2003, 46, 542.

4. Gardner, M. J.; Hall, N.; Fung, E.; White, O.; Berriman, M.; Hyman, R. W. et al. Nature 2002, 419, 498.

5. Werbovetz, K. A. Curr Med. Chem. 2000, 7, 835.

6. For reviews see: (a) Rosenthal, P. J. Curr. Opin. Hematol. 2002, 9, 140. (b) Blackman, M. J. Curr. Drug Targets 2000, 1, 59. 7. Swissprot accession number of PfA-M1: O96935.

8. Allary, M.; Schrevel, J.; Florent, I. Parasitology 2002, 125, 1. 9. Florent, I.; Derhy, Z.; Allary, M.; Monsigny, M.; Mayer, R.; Schrevel, J. Mol. Biochem. Parasitol. 1998, 117, 37.

10. Lima, P. d. C.; Barreiro, E. J.; Avery, M. A. Abstracts of Papers, 223rd ACS National Meeting, Orlando, FL, USA, April 7-11, 2002; American Chemical Society: Washington, DC, 2002; MEDI-176.

11. (a) Chan, W. W.; Dennis, P.; Demmer, W.; Brand, K. J. Biol. Chem. 1982, 257, 7955. (b) Hernandez, J. F.; Soleilhac, J. M.; Roques, B. P.; Fournie-Zaluski, M. C. J. Med. Chem. 1988, 31, 1825.

12. Ryckebusch, A.; Deprez-Poulain, R.; Debreu-Fontaine, M.-A.; Vandaele, R.; Mouray, E.; Grellier, P.; Sergheraert, C. Bioorg. Med. Chem. Lett. 2002, 12, 2595.

13. Graf von Roedern, E.; Grams, F.; Brandstetter, H.; Moroder, L. J. Med. Chem. 1998, 41, 339.

14. Native PfA-M1 was purified according to the procedure described in ref 9, and diluted 10 times in Tris- $\mathrm{HCl}$ buffer $(25$ $\mathrm{mM}$; pH 7.4) before use. The assays were set up in 96-well plates. The compounds were tested at a final concentration of $10 \mu \mathrm{M} .33 \mu \mathrm{L}$ of purified PfA-M1 were pre-incubated $10 \mathrm{~min}$ at $\mathrm{rt}$ with $33 \mu \mathrm{L}$ of the inhibitor $(30 \mu \mathrm{M}$ in Tris- $\mathrm{HCl}$ buffer, $0.3 \%$ DMSO $) .33 \mu \mathrm{L}$ of the substrate Leu-pNA $\left(K_{\mathrm{m}}=0.1\right.$ $\mathrm{mM}) 0.3 \mathrm{mM}$ in Tris- $\mathrm{HCl}$ buffer were then added. The reaction kinetics was followed on a UV-microplate reader MultiskanRC (Labsystems, Finland) at $405 \mathrm{~nm}$. The control activity was determined by incubating the enzyme in the same conditions without inhibitor. Bestatin was used as the reference inhibitor. The statistical $Z^{\prime}$ factor for the test (Zhang, J. H.; Chung, T. D.; Oldenburg, K. R. J. Biomol. Screen. 1999, 4,67 ) was 0.82 , allowing activities to be determined with a single point with a $95 \%$ confidence. Initial velocities are expressed in $\mu \mathrm{mol} . \mathrm{min}^{-1}$. Data were normalized to the con- trols that represent $V_{\max }$. For the $\mathrm{IC}_{50}$ values determination, initial velocities were plotted as a function of inhibitor concentration.

15. P. falciparum strains were maintained continuously in culture on human erythrocytes as described by Trager and Jensen (Science 1976, 193, 673). In vitro antiplasmodial activity was determined using a modification of the semi-automated micro-dilution technique of Desjardins et al. (Antimicrob. Agents Chemother. 1979, 16, 710). P. falciparum CQ-resistant FcB1 (Colombia) strain was used. Stock solutions of CQ-diphosphate and test compounds were prepared in sterile distilled water and DMSO, respectively. Drug solutions were serially diluted with culture medium and introduced to asynchronous parasite cultures $(0.5 \%$ parasitemia and $1 \%$ final hematocrite) on 96 -well plates for $24 \mathrm{~h}$ at $37^{\circ} \mathrm{C}$ prior to the addition of $0.5 \mu \mathrm{Ci}$ of $\left[{ }^{3} \mathrm{H}\right]$ hypoxanthine $(1-5 \mathrm{Ci} / \mathrm{mmol}$; Amersham, France) per well, for $24 \mathrm{~h}$. The growth inhibition of each drug concentration was determined by comparison of the radioactivity incorporated into the treated culture with that in the control culture (without drug) maintained on the same plate. The $\mathrm{IC}_{50}$, as obtained from the drug concentration-response curve were expressed as mean \pm standard deviations, determined from three independent experiments. The DMSO concentration never exceeded $0.1 \%$ and did not inhibit the parasite growth.

16. Microsomal aminopeptidase $\mathrm{N}$ from porcine kidney (EC 3.4.11.2) was purchased from Sigma-Aldrich France, as a suspension in $3.5 \mathrm{M}\left(\mathrm{NH}_{4}\right)_{2} \mathrm{SO}_{4}$ solution. Before use, it was diluted 600 times in Tris- $\mathrm{HCl}$ buffer $(25 \mathrm{mM}$; pH 7.4. The assays were set up in 96-well plates and proceeded like for PfA-M1 with the same substrate Leu-pNA $\left(K_{\mathrm{m}}=0.13 \mathrm{mM}\right)$. The $\mathrm{Z}^{\prime}$ factor of the test was 0.80 allowing activities to be determined with a single point with a $95 \%$ confidence. The reference inhibitor was bestatin.

17. 33. (3TFA): NMR (DMSO- $\left.d_{6}\right){ }^{1} \mathrm{H} \delta$ ppm $0.80-0.84$ (m; $14 \mathrm{H}) ; 1.10-1.26(\mathrm{~m} ; 5 \mathrm{H}) ; 1.27-1.90(\mathrm{~m} ; 6 \mathrm{H}) ; 2.75-3.58(\mathrm{~m}$; $14 \mathrm{H}) ; 6.89(\mathrm{~d} ; J=7.1 \mathrm{~Hz} ; 1 \mathrm{H}) ; 7.76(\mathrm{dd} ; J=9.0 \mathrm{~Hz} ; J=1.1 \mathrm{~Hz}$; $1 \mathrm{H}) ; 7.95(\mathrm{~s} ; 1 \mathrm{H}) ; 8.50-8.56(\mathrm{~m} ; 2 \mathrm{H}) ; 9.30\left(\right.$ br s; $\left.1 \mathrm{H} ; 2 \mathrm{NH}^{+}\right)$; 9.73 (br s; 0.5H; NHO); MALDI-TOF: $534.2\left(\mathrm{M}+\mathrm{H}^{+}\right) .34$. (2TFA): NMR $\left(\mathrm{CD}_{3} \mathrm{OD}\right){ }^{1} \mathrm{H} \delta$ ppm $0.80(\mathrm{~d} ; J=6.6 \mathrm{~Hz} ; 2 \mathrm{H})$; $0.86(\mathrm{~d} ; J=6.6 \mathrm{~Hz} ; 4 \mathrm{H}) ; 1.86-1.97(\mathrm{~m} ; 5 \mathrm{H}) ; 2.72$ (br t; $J=6.5$ $\mathrm{Hz} ; 2 \mathrm{H}) ; 2.76-2.95(\mathrm{~m} ; 4 \mathrm{H}) ; 2.96-3.21(\mathrm{~m} ; 10 \mathrm{H}) ; 3.43$ (br t; $J=6.6 \mathrm{~Hz} ; 2 \mathrm{H}) ; 3.62($ br t; $J=6.7 \mathrm{~Hz} ; 2 \mathrm{H}) ; 6.83(\mathrm{~d} ; J=6.8$ $\mathrm{Hz} ; 1 \mathrm{H}) ; 7.60(\mathrm{dd} ; J=1.7 \mathrm{~Hz} ; J=9.1 \mathrm{~Hz} ; 1 \mathrm{H}) ; 7.79$ (br s; $1 \mathrm{H})$; 8.25-8.33 (m; 2H); MALDI-TOF: $519.2\left(\mathrm{M}+\mathrm{H}^{+}\right) . \quad 35$. (2TFA): NMR (DMSO- $\left.d_{6}\right){ }^{1} \mathrm{H} \delta$ ppm $0.80-0.84(\mathrm{~m} ; 14 \mathrm{H})$; $1.10-1.26(\mathrm{~m} ; 5 \mathrm{H}) ; 1.27-1.90(\mathrm{~m} ; 6 \mathrm{H}) ; 2.75-3.58(\mathrm{~m} ; 14 \mathrm{H})$; $6.90(\mathrm{~d} ; J=7.1 \mathrm{~Hz} ; 1 \mathrm{H}) ; 7.78(\mathrm{dd} ; J=9.0 \mathrm{~Hz} ; J=1.9 \mathrm{~Hz} ; 1 \mathrm{H})$; $7.95(\mathrm{~d} ; J=1.8 \mathrm{~Hz} ; 1 \mathrm{H}) ; 8.51(\mathrm{~d} ; J=9.0 \mathrm{~Hz} ; 1 \mathrm{H}) ; 8.56(\mathrm{~d} ;$ $J=7.0 \mathrm{~Hz} ; 1 \mathrm{H}) ; 8.91$ (br s; $0.6 \mathrm{H} ; \mathrm{NHO}) ; 9.34$ (br s; $1.3 \mathrm{H}$; $\left.2 \mathrm{NH}^{+}\right) ; 10.75$ (br s; $\left.0.6 \mathrm{H} ; \mathrm{OH}\right) ;$ MALDI-TOF: 575.3 $\left(\mathrm{M}+\mathrm{H}^{+}\right)$.

18. In-vitro inhibition of haem polymerization induced by lipids, unpublished data (see ref 3 for protocol). 